\title{
The Theory of Achievement Motivation Revisited: The Implications of Inertial Tendencies
}

\author{
William Revelle and Edward J. Michaels \\ Northwestern University
}

\begin{abstract}
'The basic theory of achicvenent motivation as cleveloped by drkinson is reviewed, and the implications of the incrtial-tendency jostulate are examined. The classic theory of achicvement motivation is found to be a special ase of a more general theory relating task diffeulty and number of trials to performance. It is shown that the incrtial-tendency postulate implies an asynmetric, curvilinear relationship) between lask difficulty and effort, and that the degree of asymmetry is a function of the number of experimental trials and the consummatory value of failure. Ex. perimental evidence previous y viewed as contradicting the classic theory of achievement motivation is shown to be compatible with the general theory and to allow for estimation of the consummatory value of failue. Several predictions that allow for a direct test of the inerial-tendency postulate are derived. The general theory of achicvement motivation is suggested to be relevant to other theories concerned with the effects of success and failure on performance.
\end{abstract}

The theory of achievement motivation developed by J. W. Alkinson and his associates over the lasi 20 years has undergone extensive claboration since initially formalized by $\Lambda$ kkinson in 1957. Corrections and minor modilications have been added (A1kinson, 1964, 1966), and major revisions have recently been reported (Atkinson, 1974; Ráynor, 1969, 1974). We would like to show that the fundamental postulates of the theory of achievement motivation lead to interesting implications that are not normally recognized, and that research previously viewed as antithetical to the theory of achievernent motivation in fact supports predictions derived from the general theory of achievement motivation. Furthermore, the significance of a previously unimport ant variable, experimental duration or length, will be explored.

'The theory of achievement motivation is composed of seven postulates and their implications:

Postulati: 1. The tendency to engage in an achievement-orienled activity $\left(T_{\mathrm{r}}\right)$ is a mullipli-

We would like to thank J. W. Alkinson for extensive and helpful criticism of an earlicr claft of this mantscript. 'The conments of ['hilij) Brickman are also appreciated.

Requests for reprints should be sent to William Revelle, Department of Psychology, Northwestern University, Wvanston, Illinois 60201. cative function of the motive to approach success $\left(M_{\mathrm{s}}\right)$, of the incentive value of success in that activity $\left(I_{s}\right)$, and of the subjective probability of successfully completing that activity $\left(P_{F}\right)$ : $T_{\mathrm{s}}=M_{\mathrm{s}} \times I_{\mathrm{s}} \times P_{\mathrm{s}}$

PosTulate, 2. The incentive value of an achievement task is equal to the complement of the probability of success. Thus, the incentive value of an achievement lask is equal to the probability of failure on that lask: $t_{\mathrm{s}}=P_{\mathrm{f}}=1-P_{\mathrm{s}}$.

Postulate 3 . The tendency to avoid engaging in a task that might result in failure $\left(T_{\mathrm{af}}\right)$ is a mulliplicative function of the strength of the motive to avoid failure $\left(M_{\mathrm{ar}}\right)$, of the (negative) incenlive value of failure $\left(I_{\mathrm{f}}\right)$, and of the prob. ability of failure $\left(P_{\mathrm{f}}\right): T_{\mathrm{t} \mathrm{f}}=M_{\mathrm{ni}} \times I_{\mathrm{E}} \times P_{{ }_{1}}$.

Postula'T 4. The incentive value of failure is equal to the negative of the probability of success: $I_{\mathrm{f}}=\ldots I_{\mathrm{s}}$.

P'ostulate 5. The resultant tendency $\left(T_{\mathrm{r}}\right)$ to engage in an achievement task is the algebraic sum of the tendency to engage in an achievement task, of the lendency to avoid engaging in a task that might resull in failure, and of other ex trinsic motivational tendencies $\left(T_{\mathrm{P} \times 1}\right): T_{\mathrm{r}}=T_{\mathrm{H}}$ $+T_{\mathrm{at}}+T_{\mathrm{ext}}$.

Collecting terms, we find that the resultant tendency to engage in an achicvoment task is a. multiplicative function of the resultant 
motive strength $\left(M_{\mathrm{s}}-M_{\mathrm{af}}\right)$ times the incentive value of success times the probability of success :

$$
\begin{aligned}
T_{\mathrm{r}}=T_{\mathrm{s}}+T_{\mathrm{af}}+T_{\mathrm{ext}}=M_{\mathrm{s}}\left(1-P_{\mathrm{s}}\right) P_{\mathrm{s}} \\
+M_{\mathrm{af}}\left(-P_{\mathrm{s}}\right)\left(1-P_{\mathrm{s}}\right)+T_{\mathrm{cxt}} \\
\therefore \quad T_{\mathrm{r}}=\left(M_{\mathrm{s}}-M_{\mathrm{ai}}\right)\left(1-P_{\mathrm{s}}\right) P_{\mathrm{s}}+T_{\mathrm{ext}} .
\end{aligned}
$$

Equation 1 is the fundamental statement of the theory of achievement motivation as formulated in 1966 (Atkinson, 1957, 1964, 1966).

There are two striking implications of Equation 1: (a) The tendency to engage in an achievement-oriented activity should be a curvilinear function of the difficulty of the task, and (b) this function should be an inverted $\mathrm{U}$ for (approach-motivated) individuals with $M_{\mathrm{s}}>M_{\mathrm{af}}$ and should be U-shaped for (avoidance-motivated) individuals with $M_{\mathrm{s}}<M_{\mathrm{af}}$. Thus, those situations that are most motivating for approach-motivated individuals will provoke the greatest resistance and the least resultant motivation for avoidance-motivated subjects. These situations will be ones in which the probability of success is equal to .5. Although there is evidence supporting this prediction of maximum motivation at .5 , there is contradictory evidence (Hamilton, 1974; Heckhausen, 1968) demonstrating a peak between .3 and $.4 .^{1}$ Similarly, while approach-motivated individuals should not be very interested in either very easy or very difficult tasks, avoidance-motivated subjects will find these the least repulsive parts of an otherwise unpleasant situation. It is assumed that these individuals engage in any achievement task because of various extrinsic sources of motivation other than achievementoriented ones. It should be pointed out that if this extrinsic motivation is not independent of the probability of success, then the resultant curves will no longer be symmetrical around .5 . Atkinson (Note 1) has suggested that approval motivation is frequently a confounding source of extrinsic motivation that results in a shift of the peak of the ideal distribution from .5 toward .4 .

Raynor (1969) has suggested a modification of the theory stated in Equation 1 by pointing out that tasks differ in their relevance to future goals. In situations in which the only goal is the problem at hand, Equation 1 is adequate. But for those situations in which achieving an ultimate goal is contingent upon successfully completing a series of intervening tasks, Equation 1 needs to be modified to include the final goal as well as the goals of all the other intervening tasks along the "contingent path" (Raynor, 1969). "This results in Postulate 6.

Postulate 6. The motivation induced by an ultimate goal $\left(T_{\mathrm{r}_{n}}\right)$ is the sum of the motivations induced by each separate subgoal:

$T_{\mathrm{r}_{n}}=\sum_{i=1}^{n}\left[\left(M_{\mathrm{s}}-M_{\mathrm{af}}\right) P_{\mathrm{B}_{i \mathrm{o}}}\left(1-P_{\mathrm{A}_{\mathrm{i}}}\right)+T_{\mathrm{ixt}}\right]$,

where $P_{\mathbf{s}_{i 0}}$ is the probability of completing the ith task given that the present task is about to be undertaken.

Clearly, the probability of completing an intervening stage depends upon the products of the difficulty of this stage, $P_{s_{j}}$, and of the preceding stages; that is,

$$
P_{B_{i 0}}=\prod_{j=1}^{i} P_{B_{j}}
$$

Equation 2 is the general form for the resultant tendency to engage in an achievement-related task given the theory of achievement motivation as extended by Raynor (1969). When the length of the contingent path is 1 (i.c., when the final goal is that of the task at hand), $n=1$ and Equation 2 reduces to Equation 1. The implications of Equation 2 are that, for positively motivated individuals, the most: motivating lask is one of intermediate difficulty if that task is an end in itself, but otherwise, the longer the contingent path, the easier the preferred level of difficulty becomes. Evidence supporting this more general statement of achievement motivation is reviewed by Raynor (1974).

\section{INERTIAL TLNDENCIES}

A major modification to the theory of achievement motivation was tentatively introduced by Atkinson and Cartwright (1964),

\footnotetext{
1 Heckhausen has suggested that the peak between .3 and .4 can be accounted for if Postulate 2 is modified to the form $I_{\mathrm{s}}=.7-P_{\mathrm{B}}$, or if there is a nonlinear, concave relationship between $P_{\mathrm{a}}$ and $I_{\mathrm{s}}$.
} 
Atkinson (1964), and Weiner (1965). This is the concept of inertial tendency, which has been more fully developed by Atkinson and Birch (1970, 1974). Recalling the Zeigarnik effect, Atkinson and Cartwright (1964) introduced the inertial-tendency postulate:

Postul. 1 Tr: 7. An action tendency, once aroused, will persist until expressed in behavior.

In other words, the tendency to engage in an achicvement-oriented task will persist until the task is successfully completed. 'Thus, the strength of the immediate tendency to achieve is a function of the strength of the previously aroused but unsatisfied motivation (the inertial tendency) plus the additional strength of the tendency to achieve newly aroused by the immediate stimulus situation. In the case of a subject engaged in repeated trials on the same lask, success on a trial reduces achievement motivation (a consummatory effect), while failure does not. 'Thus, for positively motivated subjects, there is more motivation on a trial following a failure trial than following a success trial. Evidence in favor of this prediction is reported by Weiner $(1965,1966)$.

In in elaboration of Postulate 7, Atkinson and Birch (1970) suggested that merely engaging in a task produces some consummatory effect (perhaps related to the effort required). They stated that change in an action tendency varies as a function of the instigating forces, $\left(M_{\mathrm{s}}-M_{\mathrm{a}}\right)\left(1-P_{\mathrm{s}}\right)\left(P_{\mathrm{s}}\right)+T_{\mathrm{ext}}$, as well as of the consummatory effect of the previously aroused level of the action tendency. Thus, the action tendency on the $k+1$ trial should be the sum of this instigating force and of the action tendency on the $k$ th trial less the consummatory effect from the $k$ th trial:

$$
\begin{aligned}
T_{\mathrm{r}_{k+1}}=\left(M_{\mathrm{s}}-M_{\mathrm{at}}\right) & \left(1-P_{\mathrm{s}}\right)\left(P_{\mathrm{s}}\right) \\
& +T_{\mathrm{r} \times \mathbf{x} t}+T_{\mathrm{r}_{k}}(1-c) .
\end{aligned}
$$

Although no specific values can be estimated for $c$ (the consummatory value), intuition and scanty data (e.g., \%eigarnik, 1927/1938) suggest that there is more consummatory value associated with success than with failure. 'That is, there should be either a greater reduction or a smaller increase in motivation following success than following failure. If Postulate 2 is accepted, then the finding of Weiner (1965) that positively motivated individuals try harder on trials following failure than on trials following success lends support to Equation 3. However, if Heckhausen's (1968) criticisms of Postulate 2 are accepted, then Weiner's data are inconclusive (see Footnote 1). Assuming for the moment that $c$ is at least as great following success as following failure $\left(c_{\mathrm{s}} \geq c_{\mathrm{f}}\right)$, an examination of alternative values for $c$ results in several special cases. When
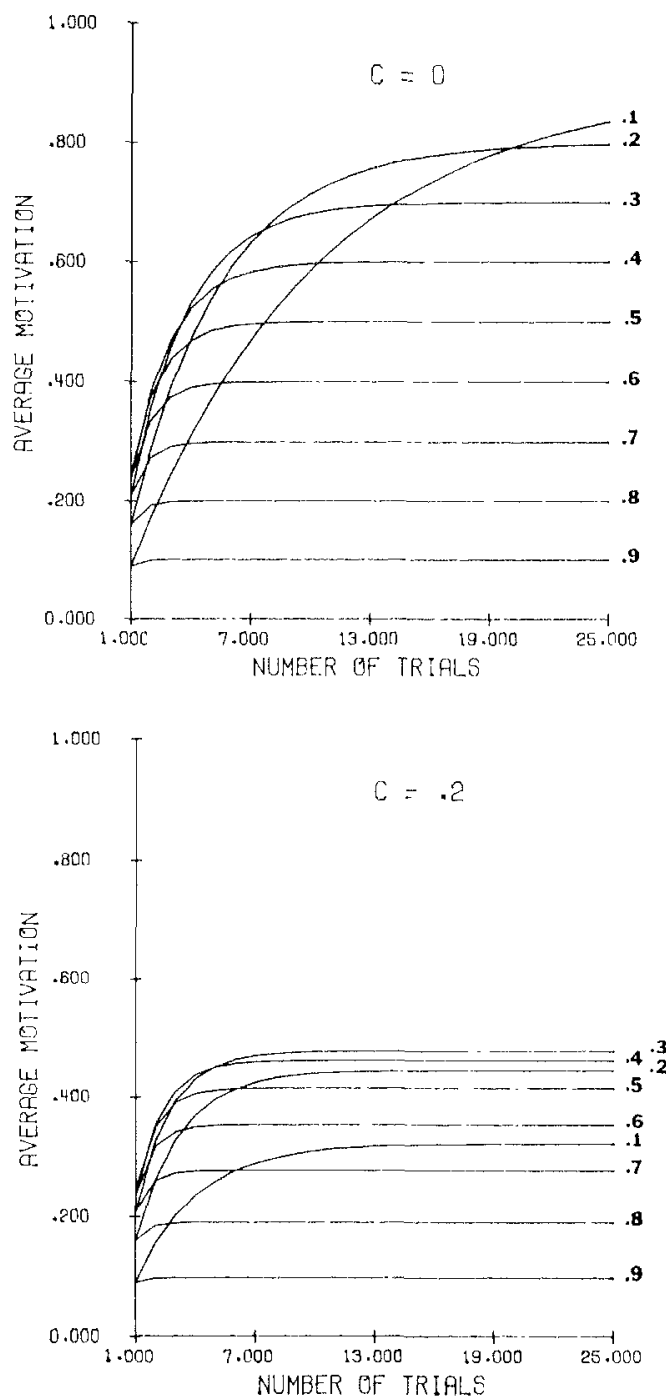

Figure 1. Expected level of motivation as a function of experimental trials and task difficulty. (The values are the level of motivation expected on the $n$th trial, where $n$ ranges from 1 to 25 and the probability of success $=.1, .2, .3, .4, .5, .6, .7, .8$, and $.9 . c$ is the consummatory value of failure. $M_{\mathrm{s}}$ is assumed to be equal to 1 and $M_{\text {af }}$ equal to 0 .) 
$c_{\mathrm{s}}=c_{\mathrm{f}}=1$, Equation 3 reduces to Equation 1 and the inertial-tendency postulate is abandoned. If $c_{\mathrm{f}}=0$ and $c_{\mathrm{s}}=1$, then motivation is a linearly increasing function of the number of trials since the last success:

$$
\begin{aligned}
& T_{\mathrm{r}_{k}}=k\left(T_{\mathrm{r}_{1}}\right) \\
& \quad=k\left[\left(M_{\mathrm{s}}-M_{\mathrm{nf}}\right)\left(1-P_{\mathrm{s}}\right) P_{\mathrm{s}}+T_{\mathrm{cxt}}\right] .
\end{aligned}
$$

For $1 \geq c_{\mathrm{f}}>0$ and $c_{\mathrm{s}}=1$, motivation is a negatively accelerated but positively increasing function of the number of trials since the last success.

For all of these cases except $c_{\mathrm{s}}=c_{\mathrm{f}}=1$, the number of trials since the last success is an important variable. But this is, of course, a function of the difficulty of the task. That is, the more difficult the task, the more likely it is that there will be many trials intervening between successes. The inertial-tendency principle thus implies that there is yet another important variable to be added to the theory of achievement motivation: the number of trials over which behavior is studied.

Equation 3 describes the change of motivation from Trial $k$ to Trial $k+1$. For values of $0 \leq c_{\mathrm{r}} \leq 1$ and $c_{\mathrm{s}}=1$, the expected value of $T_{\mathrm{r}}$ can be found in the following manner. $T_{\mathrm{r}_{\hat{k}+1}}=T_{\mathrm{r}_{1}}$ on the trial immediately following a successful trial, since the effect of the inertial tendency from the preceding trial is reduced to zero by the consummatory effect of success. $T_{\mathrm{r}_{k+1}}=T_{\mathrm{r}_{1}}+T_{\mathrm{r}_{k}}\left(1-c_{\mathrm{f}}\right)$ on a trial immediately following a failure trial. letting

$$
T_{\mathrm{r}_{1}}=\left(M_{\mathrm{s}}-M_{\mathrm{at}}\right)\left(1-P_{\mathrm{s}}\right) P_{\mathrm{s}}+T_{\mathrm{cxt}},
$$

and recognizing that after $k$ trials following success that $T_{k}=\left(T_{\mathrm{r}_{1}} / c_{\mathrm{f}}\right)\left(1-e^{-c_{\mathrm{f}} k}\right)$ (Atkinson \& Birch, 1970), then it is possible to find the expected value, $E(T)$, of the tendency to engage in an achievement task on Trial $n$ by summing the $n$ products of the probability of having $k$ trials since the last success times the value of the motivational tendency after $k$ such trials $\left(T_{k}\right)$. That is,

$E(T)=\sum_{k=1}^{n} P_{s} T_{k}\left(1-P_{\mathrm{s}}\right)^{k-1}$

$$
+T_{n}\left(1-P_{s}\right)^{n-1} \text {. }
$$

But,

$$
T_{k}=\left(T_{\mathrm{r}_{\mathrm{l}}} / c_{\mathrm{f}}\right)\left(1-e^{-c_{\mathrm{f}} k}\right)
$$
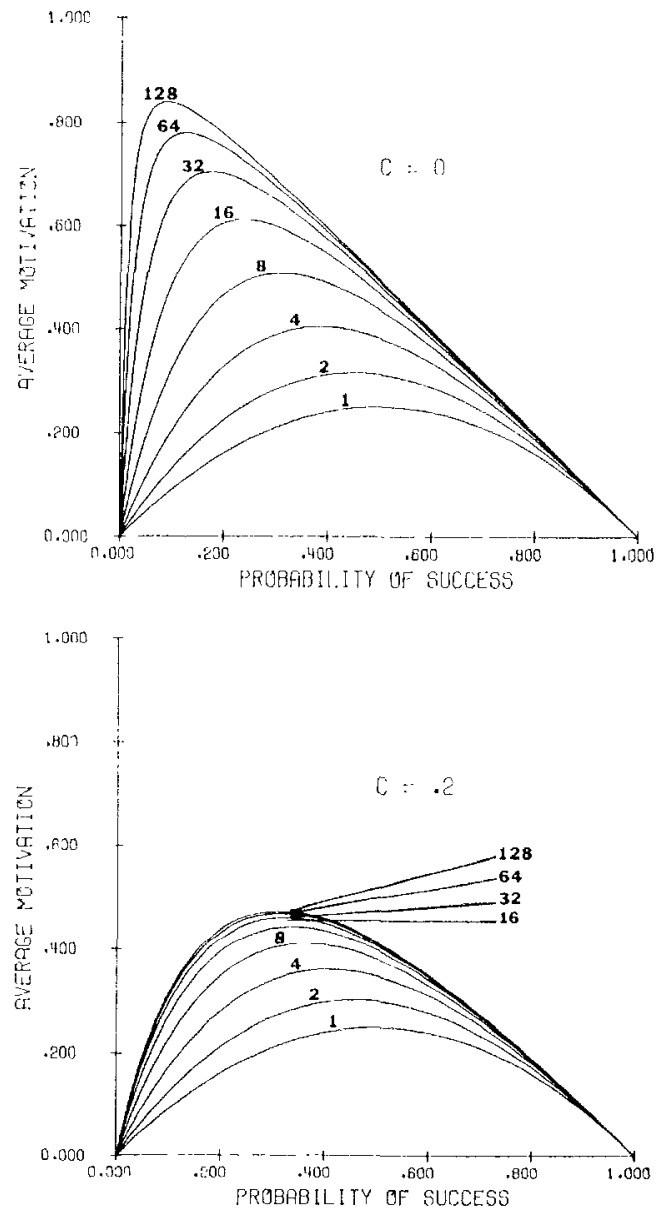

Figure 2. Fxpected level of motivation as a function of task difficulty (probability of success) and total number of experimental trials. (The expectation is taken over Trials 1 through $n$ for $n=1,2,4,8,16,32$, 64 , and $128 . c$ is the consummatory value of failure. $M_{\mathrm{s}}$ is assumed to be equal to 1 and $M_{\text {af }}$ equal to 0. )

so,

$$
\begin{aligned}
E(T)=P_{\mathrm{s}} & \left(T_{\mathrm{r}_{1}} / c_{\mathfrak{l}}\right) \sum_{k=1}^{n}\left(1-e^{-c_{\mathfrak{f}} k}\right)\left(1-P_{\mathrm{s}}\right)^{k-1} \\
& +\left(T_{\mathrm{r}_{1}} / c_{\mathfrak{l}}\right)\left(1-e^{-c i k}\right)\left(1-P_{\mathrm{s}}\right)^{n-1}
\end{aligned}
$$

$T_{r_{1}}$ is the motivation for a single trial as defined in Equation 1.

Figure 1 displays the expected level of motivation on the $N$ th trial for a positively motivated subject as a function of the number of trials and the probability of success on each trial for the cases of $c_{\mathrm{f}}=0$ and .2 and $c_{\mathrm{s}}=1$. Figure 2 displays the average level of motivation across trials as a function of task difficulty 
for an experiment terminating in $n$ trials for eight different values of $n$. As can be seen, the symmetric, curvilinear prediction of the early theory of achievement motivation. (Equation 1) is recovered as a special case for $n=1$. As $n$ becomes larger (greater than 30 for $c_{\mathrm{f}} \geq .1$ ), Equation 4 results in a stable (over trials) ordering of motivation for different levels of task difficulty (Figure 1). Rather than the symmetric function required by Equation 1 , there is a greater expected level of motivation for difficult tasks than for easy tasks, with the peak obtained between .2 and .3 (Figure 2). (Larger values of $c_{\mathrm{f}}$ result in a shift of the peak toward .5, but the basic asymmetry remains. For $c_{\mathrm{f}}=.5$, the peak is between .35 and .47 . For $c_{f}=0$ and $c_{\mathrm{s}}=1$, $E(T)$ tends toward $\left(1-P_{\mathrm{s}}\right)$ as $n \rightarrow \infty$.)

Although not shown here, the variance of the motivation is also directly proportional to task difficulty for moderate to large numbers of trials. This is because where $P_{B}$ is low, long series of failures are common, interspersed with a few successes. This allows effort to build to very strong levels during repeated failures and to drop to weak levels immediately after the rare successes. Average effort is high but so is variability of effort.

It should be pointed out that an implicit assumption in the derivation of Equation 4 from Equation 3 is that the subjective probability of success remains constant across trials. This is at odds with the assumptions made by Feather (1963) and by Weiner (1965, 1966) in their investigations, but it is necessary to solve Equation 3. It is not an altogether unreasonable assumption if the subjective probability of success closely approximates the actual ratio of successful trials to total number of trials; that is, if

$$
P_{\mathrm{s}} \approx \frac{\text { frequency of success }}{\text { number of trials }} \text {. }
$$

Although $P_{\text {s }}$ as specified in. Fiquation 5 is unstable for the first few trials, it will rapidly approach a stable value. There are indications that Equation 5 is a reasonable assumption. For example, Jones, Rock, Shaver, Goethals, and Ward (1968) found that over many trials, subjects' subjective estimates of $P_{s}$ closely corresponded to the ratio of the number of successes to the number of trials. However, there is a slight recency bias in that more recent successes and failures are weighted more heavily in subjective estimates. The general theory of achievement motivation proposed here applies primarily to later trials in a series, after $P_{\mathrm{s}}$ has stabilized.

An additional assumption in the derivation of Equation 4 from Equation 3 is that the consummatory value of a successful trial is not only greater than that of a trial resulting in failure (e.g. Weiner, 1966) but that it is equal to 1. This assumption is necessary in order to have a reasonable number of elements in Equation 4. Given the assumptions of $c_{\mathrm{s}}=1$, Equation 4 requires $n$ elements to calculate the expected motivation on the $n$th trial. Without this assumption, $2^{n-1}$ elements are necessary. Thus, even for a limited number of trials, with $c_{\mathrm{B}}<1$ it is extremely difficult to evaluate Equation 4.

It is interesting to note that the relationship shown in Figure 2 is very similar to the relationship postulated by Raynor (1969) between $P_{\mathrm{s}}$ and effort as a function of the length of a contingent path, except that here the relationship is in the opposite direction. Both Raynor's formulation and the present one depict a family of curves representing the relationship between lask difficulty and effort. For Raynor, the shape of the curve is determined by the length of the contingent path (the number of dependent or linked successive trials leading to some ultimate goal), whereas the shape of the curves in Figure 2 is determined by the number of noncontingent, independent, or unlinked successive trials, each an end in itself. Both Raynor's formulation and the present one reduce to the classic curvilinear relationship when the number of trials is one. However, as the number of trials increases, the direction of the relationship between $P_{\mathrm{s}}$ and effort depends upon whether trials are contingent or noncontingent.

\section{EMPTRICAL Evidence}

Unexpected support for the prediction that effort is related to task dificulty for repeated tasks, as shown in Fïgures 1 and 2, comes in the form of a direct challenge to the theory of achievement motivation (locke, 1968). In a series of studies, Locke and his co-workers 
systematically varied the difficulty of tasks by varying not the task itself but rather the desired performance level defining success on the task (the goal). In a representative experiment (cited in Locke, 1968), subjects were given 40 trials on a reaction time task. They were told either to try to beat their worst previous time, beat their immediately previous time, or beat their best previous time. The empirical probabilities of success (proportion of subjects actually succeding) in each condition were $.91, .47$, and .10 , respectively, and the reaction times were slowest in the .91 condition and fastest in the .10 condition. That is, the faster the subjects were told to react (and thus the less likely they were to succeed), the faster they did react. Motivation (eflort) was directly proportional to task difficulty. 'This is not surprising from an everyday theory of behavior, but it is directly contradictory to the simple theory of achievement motivation which predicts that motivation is curvilinearly related to task difficulty and maximal for moderately difficult tasks $\left(P_{\mathrm{s}}=.5\right)$.

In a summary of 12 studies that he and his co-workers had done, Locke (1968) reported that 9 of them showed this monotonic relationship between task difficulty and task performance. In 2 of the remaining 3 studies, tasks with empirical probabilities of success of .07 and .04 led to the greates productivity. In an attompt to summarize these 12 studies, Locke converted each performance score into a standard score (standardized within experiments) which he plotted against the empirical probability of success. The rank order cotrelation was .78 , and there was no visual evidence for a curvilinear component. Locke (1968) interpreted this result as strong evidence against the theory of achievement motivation developed by Atkinson (1957).

Locke claimed his results indicated that the harder the goal, the greater the effort to atlain it. But in Locke's studies, goal difficulty (i.e., task difficulty) was confounded with goal attainment; hard goals were not often attained. From the point of view of Equation 4, hard goals lead to greater average effort, since motivation builds up with repeated failure. Thus Locke's actual finding was that average eflort is a roughly linear function of task difficulty when averaged over many trials.
This finding lends support to the theory of achievement motivation when it is expanded to include the implications of inertial tendencies (Equation 4). The overall linear relationship observed by Locke is just what would be expected from Figures 1 and 2. Calculating the expected effort as defined in Equation 4 for each of Locke's data points and for several values of $c_{p}$, we found that the product-moment correlations between simulated effort and task difficulty were $.66, .59, .51, .43, .36$, and .31 for $c_{\mathrm{f}}$ values of $0, .1, .2, .3, .4$, and .5 , respectively. Clearly, for small values of $c_{\mathrm{f}}$, the theoretical results are in reasonable agreement with Locke's empirical findings. In addition, for $c_{\mathrm{f}} \leq .1$, the exact rank order of effort values was duplicated for 7 out of 12 of Locke's studies. The worst deviation irom Locke's results occurred for extremely difficult tasks $\left(I_{\mathrm{s}}=.04, .05\right.$, and .10$)$ with only a $\mathrm{few}$ trials $(6,10$, and 5 , respectively). In these extreme cases, Locke found much higher levels of motivation than the theory predicts. This could have been due to the initial instability of the subjective level of the probability of success suggested by Equation 5 , for it is difficult for a subject to distinguish between $P_{\mathrm{s}}=.04$ and $P_{\mathrm{s}}=.15$ within five to six trials. When the minimum probability of success is restricted to being at least as great as $1 /$ (the number of trials), the correlations between task difficulty and effort values calculated from Equation 4 are .84, .79, .71, .63, .56, and .49 for $c_{\mathrm{f}}$ values of $0, .1, .2, .3, .4$, and .5 , respectively. These correlations are in striking agreement with Locke's empirical correlation of .78. (It should be pointed out that it was not possible to compare the goodness of fit of the model to the raw data, since they were not reported by Locke. Nor was it possible to test the prediction of greater effort variance for difficult tasks.)

Other support for the inertial-tendency postulate comes from another critique of the simple Atkinson theory (Hamilton, 1974). In an elegant experiment, Hamilton controlled for individual differences in determining the subjective probability of success by individually tailoring various difficulty levels in a ringtoss experiment. This was accomplished by giving the subjects 10 practice throws at each of 10 distances and calculating the true 
probability of success for each distance. Hamilton then examined free-choice preferences of distance for 10 additional tosses. He found that positively motivated individuals preferred intermediate levels of risk but with an asymmetric distribution of preference centered around .4. Negatively motivated individuals were more variable but generally preferred the most difficult levels of risk. 'The distribution of preferences for risk for the positively motivated individuals bears a striking resemblance to the motivation levels predicted by Equation 4, assuming $n=10$ and $c_{\mathrm{f}}=$.3. (An implicit assumption made here is that preference will follow relative motivation levels.) In fact, the product-moment correlation between the distribution of preferences observed by Hamilton and the efiort predicted by Equation 4 is 83 . Correlations with other $c_{\mathrm{f}}$ values were $.69, .76, .82, .82, .80$, and .69 for $c_{\mathrm{f}}$ values of $0, .1, .2, .4, .5$, and 1 , respectively. This last case $\left(c_{\mathrm{f}}=1\right)$ is of course equivalent to ignoring Postulate 7 and using Equation 1 instead of Equation 4. Data similar to those of Hamilton have been reported by Heckhausen (1968) and can be fitted in a similar manner.

\section{Some Complications}

Lest it be believed that Equation 4 can account for all criticisms of the theory of achievement motivation, some difficulties should be mentioned. The first comes from Weiner's experiment (1965), which has been used to justify the assumption of inertial tendencies. If the seven postulates that have been presented here are to be believed, then an individual with $M_{\mathrm{s}}<M_{\mathrm{n}}$ should always have less motivation than an individual with $M_{\mathrm{s}}>M_{\mathrm{a}}$. The prediction based upon the inertial-tendency postulate is that failure on the initial trial of an experiment should accentuate the differences between positively and negatively motivated individuals but that success on the initial trial should not. Success should only affect motivation for the second trial by changing the value of $P_{\mathrm{s}}$. Weiner found, however, that both motivational groups dicl equally well on the first trial (which is not predicted from the theory) and that success for the negatively motivated group led to better performance than did failure for the positively motivated group. This result cannot be obtained from the present theory. Weiner reported a similar result (better performance following success for the negative motivation group) in another study (Weiner, 1966). He attempted to explain away the Spence and Taylor funding relating anxiety and task difficulty to performance (Spence, 1958) by postulating that inertial tendencies are reduced by success for positively motivated individuals. Other research on the effects of anxicty on performance follows a jattern similar to the Weiner data (e.g. Lucas, 1952; Spence, Jarber, \& McFann, 1956).

Although Weiner reported that it does, the theory of achievement motivation as cxpressed in Postulates 1 to 7 does not account for the finding of better performance for the highly anxious (negatively motivated) subjects following success. While the theory does predict differential decreases and increases in performance for positively and negatively motivated subjects, it does not predict the cross-over effect observed by Weiner and others. Nor does it account for the initially equal (Weiner, 1966) or even superior (Spence et al., 1956) performance on the part of the highly anxious subjects on the first few trials.

Nygard (1975) has attempted to account for these discrepant results by modifying the original theory of achievement motivation to include the concept of "optimal stimulation." Nygard asserts that negatively motivated individuals find easy tasks moderately stimulating and thus positively motivating, while positively motivated individuals find such easy tasks very unstimulating and actually aversive. Thus, by postulating different processes for positively and negatively motivated individuals, Nygard (1975) is able to explain the superior performance of highly anxious (negatively motivated) subjects on easy tasks.

The previous theoretical and empirical complications suggest that the present theory of achicvement motivation is particularly relevant for positively motivated individuals and less so for negatively motivated persons. This is in accord with the recent work of Atkinson and Birch (1970, 1974), which has separated the effects of action and avoidance ("negaction") tendencies on performance and choice. 


\section{TIIEORLTICAI. PREDICTIONS}

Even with these complications, the implications of Postulate 7 for the theory of achievement motivation are far-reaching and have been discussed in some detail by Atkinson and Birch (1974). They seem to have ignored, however, the predictions that are implicit in Equation 4. Some of these predictions can be used to test the validity of Equation 4 and, indirectly, the validity of the postulate of inertial tendencies. The primary prediction for which we have evidence is that for noncontingent trials, the relationship of average effort to task difficulty varies as a function of the number of trials and $c_{\mathrm{f}}$, as in Figures 1 and 2. On single-trial tasks, the relationship is curvilinear; on many-trial tasks, the relationship is also curvilinear (assuming $c_{\mathrm{f}}>0$ ) but is markedly asymmetric. Other predictions for noncontingent trials that need to be tested include the following:

1. For positively motivated individuals, effort should be positively rclated to the number of trials since the last success.

2. For negatively motivated individuals, effort should be negatively related to the number of trials since the last success.

3. Changes in motivation following failure should be negatively correlated with changes in motivation following success.

4. The variance of measured effort should increase as task difficulty increases.

5. For any given task difficulty, the variance of effort should increase as the number of trials increases.

6. The average effort on first trials should be equivalent to the average effort on all trials immediately following successful trials, and this effort should be curvilinearly related to $P_{\mathrm{s}}$.

7. Differences in motivation between approach-motivated individuals and avoidancemotivated individuals should be maximal for difficult tasks with repeated trials.

8. Average effort should increase with task difficulty except for tasks with very low probabilities of success (less than .05).

9. For a large number of noncontingent trials, more difficult tasks should elicil greater average motivation; for a large number of contingent trials, easier tasks should elicit greater effort.
To test these predictions, and thereby to test the basis of the inertial-tendency postulate, it will be necessary to operationalize the concepts of motive, motivation, and eforl. The conventional definition of resultant achievement motive has been based on the differences between scores on a thematic apperceptive measure of need for achievement (Atkinson, 1958) and scores on measures of test anxiety (Mandler \& Sarason, 1952). The Thematic Apperception 'Test (TA'T) measures have been criticized on the basis of a lack of internal consistency (Entwisle, 1972) and defended on those same grounds (Atkinson, Bongort, \& Price, in press). Atkinson et al. (in press) argue (on the basis of computer simulations) that the inertial-tendency postulate and the theory derived from it (Atkinson \& Birch, 1970) inply that tests need not be internally consistent if they are to be proper measures of motive strength. Rather, they suggest, the best measure of motive strength is the lotal time spent imagining achieving. They report that computer simulations of their model show that total time spent can correlate quite highly with motive strength, even though there is only a low internal consistency reliability based upon scores from simulated stories told about simulated pictures. To properly assess their claim would be beyond the scope of this paper.

Other, simpler measures of motive strength have been developed by Mehrabian (1968), Hermans (1970), Edwards (1959), Jackson (1967), and French (1958). Unfortunately, the intercorrelations of these measures are clepressingly low (Fiske, 1973; Wotruba \& l'rice, 1975). There is some recent evidence (Hamilton, 1975; Wotruba \& Price, 1975) suggesting that Hermans's test might be the best altemative to the normal TAT procedure, but this needs to be confirmed.

Motivation can be operationalized in several ways. High motivation should be related to willingness to engage in a task as well as jelated to the effort applied to that task. If we assume (sce Note 1) that the majority of students at most selective colleges or universities are positively motivated, then we can test several of the implications of the inertial-tendency postulate by comparing effort on trials immediately following success or failure. On. a 
reaction time task, for instance, reaction times on trials following success feedback should be slower (less effort) than those on trials following failure feedback. Similarly, if subjects are allowed to initiate successive trials on any self-paced task, higher motivation should lead to shorter intertrial latencies. Thus, the latency between trials should be greater after success fecdback than after failure feedback. These predictions are, of course, particularly strong in the case of subjects selected for positive motive levels, but we would expect these results even for subjects not so screened.

\section{J) ISCUSSION}

Although this paper has been concerned with the implications of the inertial-tendency postulate for the theory of achievement motivation, it might be fruitful to consider its relevance to other areas of research as well. In at recent review and reformulation of the reactance and learned helplessness literature, Wortman and Brehm (1975) have suggested that individuals respond to a loss of control over a situation in a variety of ways. According to Wortman and Brehm, when subjects experience a slight loss of control, they tend to exhibit increases in task-relevant motivation (reactance). When faced with a major loss of control, however, subjects tend to give up trying and to show very low levels of motivation (learned helplessness). One way that subjects may be made to feel that they are not in control of a situation is to present them with a series of extremely difficult problems. Assume that subjects start these problems with some nonzero expectancy of success and then succeed only rarely. We can see from Figure 2 that, as the subjective probability of success slowly decreases (Equation 5), the expected tendency to engage in the task will at first increase, and then, as very low probability of success is reached, drop precipitously. The initial increase in motivation would seem to be related to the reaclance effects, and the final decrease, to the learned helplessness effects discussed by Wortman and Brehm (1975). That is, the revised theory of achievement motivation predicts that moderately difficult problems or situations (with probabilities of success ranging from .5 to .1) should be extremely motivating ("When the going gets tough, the tough get going"). On the other hand, very difficult or impossible tasks (probabilities of success less than .1) should lead to extremely low levels of motivation ("Wise people do not beat their heads against brick walls").

A related issue that has been avoided until now is the reciprocal relationship between effort and probability of success. We have discussed how the subjective probability of success determines motivation (Figures 1 and 2) but have ignored how effort affects the true probability of success. In most tasks, the harder the effort, the higher the true probability of success. In the early history of achievement motivation (prior to the postulation of inertial tendencies), it was stated that positively motivated individuals try less hard on tasks with subjective $P_{8}<.5$ than on those with $P_{\mathrm{B}}=.5$. But if effort has a positive effect on performance, and thus on the true probability of success, this implies that for more difficult tasks $\left(P_{\mathrm{s}}<.5\right)$, there should be less effort and hence an even lower true probability of success than if the probability of success were unrelated to effort. This, in turn, should lower the effort for the next trial, which in turn should reduce the true probability of success for that next trial, thus completing this positive-feedback loop. If, on the other hand, there is a carry-over of motivation from trial to trial (as predicted by the inertial-tendency postulate), then there should be more effort exerted on difficult trials, which in turn should make the true probability of success greater. Thus, rather than the positive-feedback loop and resulting unstable effects of task difficulty as predicted from the earlicr theory, with the addition of inertial tendencies, failure has a negative-feedback effect that maintains steady levels of effort over a wide range of task difficulties.

But all of this assumes that there is at monotonic relationship between effort and true probability of success. Atkinson (1974) revicwed some of the previously contradictory findings relating achievement motivation to lask performance and concluded that there is an inverted- $U$ relationship between total motivation and efficiency of task performance (i.c. the true probability of success). (iting Yerkes and Iodson (1908), Hebb (1955), Broadhurst 
(1959), and Eysenck (1966), Atkinson (1974) argued for the plausibility of such a curvilinear relationship and proposed that the study of academic performance should include a consideration of ability and motivation as well as efficiency, which, he claimed, is curvilinearly related to total motivation. If efficiency (and thus the true probability of success) is curvilinearly related to motivation, and motivation is related to the subjective probability of success (Equation 4), some very complicated interactions result, and the problems of predicting achievement-related behavior become exceedingly difficult. In general, however, the inertial-tendency postulate leads to the prediction of greater stabilities of performance over a wider range of task difficulties than does the theory of achievement motivation without inertial tendencies.

In conclusion, it seems that the theory of achievement motivation originally proposed by Atkinson (1957) is a special case of a much more powerful and more general theory. This paper's emphasis upon the complexity of the inertial-tendency concept when the probability of success is also considered implies that some of the predictions derived from the concept of inertial tendencies need to be developed further. The general conclusion, however, is that the concept of inertial tendencies allows the theory of achievement motivation to account for a much wider range of motivational phenomena than previously. Finally, the present theory highlights the importance for psychology not only to study individual behavioral events but to take into account successive dependencies in behavior, that is, the fact that previous outcomes and their patterning influence subsequent outcomes.

\section{REIERENCE NOTE}

1. Atkinson, J. W. Personal communication, June 1975.

\section{REFERENCES}

Atkinson, J. W. Motivational detcrminants of risktaking behavior. Psychological Reviev, 1957, 61,359372.

Atkinson, J. W. (Ed.). Motives in fanlasy, action, and sociely. Princeton, N. J. : Van Nostrand, 1958.

Atkinson, J. W. An introduction to motitation. Princeton, N. J.: Van Nostrand, 1964.

Atkinson, J. W, Motivational determinants of risktaking behavior. In J. W. Atkinson \& N. 'T. Feather
(Eds.), $A$ theory of achievement motivation. New York: Wiley, 1966.

Atkinson, J. W. Strength of motivation and efficiency of performance. In J. W. $\Lambda$ tkinson \& J. O. Raynor (E.ls.), Motivation and achievement. Washingron, D.C.: V. H. Winston, 1974.

Atkinson, J. W., \& Birch, D. The dynamics of action. New York: Wiley, 1970.

Atkinson, J. W., \& Birch, D. The dynamics of achievement-oriented activity. In J. W. Atkinson \& J. 0. Raynor (Lds.), Motivation and achievement. Washington, D.C.: V. H. Winston, 1974.

Atkinson, J. W., Bongort, K., \& Price, L. H. Explorations using computer simulations to comprehend thematic apperceptive measurement of motivation. Molivation and Limotion, in press.

Atkinson, J. W., \& Cartwright, D. Some neglected variables in contemporary conceptions of decision and performance. I'sychological Reports, 1964, 14, 575-590.

Broadhurst, P. L. The interaction of task difficulty and motivation: The Yerkes-Dodson Law revived. Acta Psychologica, 1959, 16, 321-338.

Edwards, A. L. Mannal-Lidwards Personal Preference Schedule (rev. ed.). New York: Psychological Corporation, 1959.

Intwisle, D. E. 'To dispel fantasies about fantasy-based measures of achievcment motivation. Psychological Bulletin, 1972, 77, 377-391.

Eysenck, H. J. Personality and experimental psychology. British Psychological Society Bulletin, 1966, 10, $1-28$.

Feather, N. T. Persistence at a dificult task with alternative task of intermediate difliculty. Journal of Abnormal and Social Psycloology, 1963, 66, 604-609.

Fiske, D. W. Can a personality construct be validated empirically? Psychological Bulletin, 1973, 80, 89-92.

French, E. G. 1)evelopment of a measure of complex motivation. In J. W. Atkinson (Ed.), Motives in fantasy, action, and sociely. Princeton, N. J.: Van Nostrand, 1958.

Hamilton, J. O. Motivation and risk taking behavior: A test of Atkinson's theory. Journal of Personality and Social Psychology, 1974, 29, 856-864.

Hamilton, J. O. Prediction of persistence and performance with the Hermans Prestatic Motivation Test. Ziducation and Psychological Measurement, 1975, 35, 915-920.

Hebls, D. O. Drives and the C.N.S. (conceptual nervous system). Psychological Review, 1955, 62, 243-254.

Heckhausen, H. Achievement motive research: Current problems and some contributions towards a general theory of motivation. In W. J. Arnold (Ed.), Nebraska Symposium on Motivation (Vol. 16). Lincoln: University of Nebraska Press, 1968.

Hermans, H. J. M. A questionnaire measure of achieve. ment motivation. Journal of Applied Psychology, $1970,54,353-363$.

Jackson, D. N. Personality Research Form Manual. Goshen, N.Y.: Research P'sychologists Press, 1967.

Jones, E. E., Rock, L., Shaver, K. G., Goethals, G. R., \& Ward, L. M. Pattern of performance and ability attribution: An unexpected primacy effect. Journal 
of Personality and Social Psychology, 1968, 10, 317340.

Locke, E. A. Toward a theory of task motivation and incentives. Organizational Behavior and It aman Performance, 1968, 3, 157-189.

Lucas, J. D. The interactive effects of anxiety, failure and interserial cluplication. American Joumal of Psychology, 1952, 65, 59-66.

Mandler, G., \& Sarason, S. B. A study of anxiety and learning. Journal of A bnormal and Social Psychology, 1952, 47, 166-173.

Mehrabian, $\Lambda$. Male and female scales of the tendency to achicve. Liducalional and Psychologicul Measuremenl, 1968, 28, 493-502.

Nygard, R. $\Lambda$ reconsideration of the achievement motivation theory. IAtropean Journal of Social Psychology, $1975,5,61-92$.

Raynor, J. O. Future orientation and motivation of immediatc activity: $\Lambda$ n claboration of the theory of achievement motivation. Psychological Review, 1969, $76,606-610$.

Raynor, J. O. Iruture orientation in the study of achievement motivation. In J. W. Atkinson \& J. O Raynor (Erls.), Motivation and achievement. Washington, D.C. : V. II. Winston, 1974.

Spence, K. W. A theory of emotionally based drive (D) and its relation to performance in simple learning situations. American Psychologist, 1958, 13, 131-141.

Spence, K. W., larber, I. F., \& Mclann, H. H. The relation of anxiety (drive) level to performance on competitional and noncompetitional paired-associates learning. Journal of Experimental Psychology, 1956, 52, 296-310.

Weiner, B. 'The effects of unsatisfied achicvement motivation on persistence and subsequent performance. Joumal of Personality, 1965, 33, 428-442.

Weiner, B. Role of success and failure in the learning of casy and complex tasks. Journal of Personality and Social Psychology, 1966, 3, 339-344.

Wortman, C. B., \& Brehm, J. W. Responses to uncontrollable outcomes: An integration of reactance theory and the learned helplessness model. In L. Berkowitz (Fd.), Advances in experimental social psychology (Vol. 8). Now York: Academic Press, 1975.

Wotruba, T. R., \& I'rice, K. F. Relationshius among four measures of achievement motivation. Lducalional and Psychological Measuremenl, 1975, 35, 911914.

Yerkes, R. M., \& J)odson, J. I), 'The relation of strength of stimulus to rapidity of habit formation. Journal of Comparative and Neurological Psychology, 1908, 18, 459-482.

Zeigarnik, B. [On finished and unfinished lasks.] In W. D. Ellis (Ld.), A source book of Gestalt psychology. New York: Harcourt, Brace, 1938. (Reprinted and translated from Psychological Forsching, 1927, 9, 1-85.)

(Received December 31, 1975; revision received May 17, 1976) 